\title{
Recent patent applications related to zinc fingers
}

\begin{tabular}{|c|c|c|c|c|c|}
\hline Patent number & Description & Assignee & Inventor & $\begin{array}{c}\text { Priority } \\
\text { application date }\end{array}$ & $\begin{array}{c}\text { Publication } \\
\text { date }\end{array}$ \\
\hline US 20110086015 & $\begin{array}{l}\text { A zinc three-finger binding domain that targets a } \\
\text { nucleotide sequence selected from SEQ ID NO: } 1 \\
\text { and } 2 \text {; provides new zinc finger proteins and zinc } \\
\text { finger nucleases useful in repairing the CFTR gene } \\
\text { and treating cystic fibrosis. }\end{array}$ & $\begin{array}{l}\text { Joung JK, Maeder M, } \\
\text { McCray P }\end{array}$ & $\begin{array}{l}\text { Joung JK, Maeder M, } \\
\text { McCray P }\end{array}$ & $4 / 16 / 2008$ & 4/14/2011 \\
\hline $\begin{array}{l}\text { WO } 2011032721 \text {, } \\
\text { EP } 2308998\end{array}$ & $\begin{array}{l}\text { Detection of anogenital cancer or its precursor in a } \\
\text { sample comprising determining the methylation } \\
\text { status of astrotactin } 1 \text { (ASTN1) and zinc finger } \\
\text { protein transcription factor (ZNF671). }\end{array}$ & $\begin{array}{l}\text { Friedrich Schiller } \\
\text { University of Jena } \\
\text { (Jena, Germany) }\end{array}$ & $\begin{array}{l}\text { Dürst M, Hansel A, } \\
\text { Steinbach D }\end{array}$ & $9 / 18 / 2009$ & $\begin{array}{l}3 / 24 / 2011 \\
4 / 13 / 2011\end{array}$ \\
\hline US 20110070205 & $\begin{array}{l}\text { An isolated adult stem cell capable of proliferating } \\
\text { and differentiating into at least two of ectoderm, } \\
\text { mesoderm or endoderm, and expresses at least one } \\
\text { of octamer-binding transcription factor } 4 \text { (Oct-4), } \\
\text { Kruppel-like factor } 4 \text { (KLF-4), Nanog, SRY (sex } \\
\text { determining region Y)-box } 2 \text { (Sox-2), zinc finger } \\
\text { family transcription factor Rex-1, growth } \\
\text { differentiation factor-3 (GDF3) and Stella. }\end{array}$ & $\begin{array}{l}\text { Brigham \& Women's } \\
\text { Hospital (Boston) }\end{array}$ & $\begin{array}{l}\text { Crawford KD, } \\
\text { Southgate C }\end{array}$ & $5 / 3 / 2007$ & $3 / 24 / 2011$ \\
\hline WO 2011023999 & $\begin{array}{l}\text { The use of a nucleotide that encodes a protein } \\
\text { including an amino acid sequence having specific } \\
\text { percent homology to human zinc finger transcription } \\
\text { factor DNA binding domain; useful in the treatment } \\
\text { of, e.g., peripheral neuropathy. }\end{array}$ & $\begin{array}{l}\text { Ark Therapeutics } \\
\text { (London) }\end{array}$ & Liu D, Zachary IC & $8 / 25 / 2009$ & $3 / 3 / 2011$ \\
\hline $\begin{array}{l}\text { WO 2010107493, } \\
\text { US } 20100291048\end{array}$ & $\begin{array}{l}\text { A zinc finger DNA-binding domain that binds to a } \\
\text { target site in a chemokine (C-X-C motif) receptor } 4 \\
\text { (CXCR4) gene. }\end{array}$ & $\begin{array}{l}\text { Sangamo BioSciences } \\
\text { (Richmond, CA, USA) }\end{array}$ & $\begin{array}{l}\text { Holmes MC, Miller JC, } \\
\text { Wang J }\end{array}$ & 3/20/2009 & $\begin{array}{l}9 / 23 / 2010 \\
11 / 18 / 2010\end{array}$ \\
\hline $\begin{array}{l}\text { WO } 2010115368 \text {, } \\
\text { CN } 101875689\end{array}$ & $\begin{array}{l}\text { A zinc finger protein transcription factor } \\
\text { comprising a polypeptide including amino acids at } \\
\text { position } 42-85 \text { of a } 303 \text {-amino-acid sequence; } \\
\text { useful for producing a transgenic plant having } \\
\text { improved drought and salt tolerance. }\end{array}$ & $\begin{array}{l}\text { Shanghai Institutes for } \\
\text { Biological Sciences, } \\
\text { Chinese Academy of } \\
\text { Sciences (Shanghai) }\end{array}$ & $\begin{array}{l}\text { Chao D, Gao J, Huang X, } \\
\text { Lin H, Shi M, Zhu M }\end{array}$ & $4 / 8 / 2009$ & $\begin{array}{c}10 / 14 / 2010 \\
11 / 3 / 2010\end{array}$ \\
\hline WO 2010089559 & $\begin{array}{l}\text { A small interfering RNA (siRNA) or short hairpin } \\
\text { RNA (shRNA) comprising a nucleic acid sequence. } \\
\text { The siRNA or shRNA is an inhibitor of cyclin- } \\
\text { dependent kinase inhibitor } 1 A \text { interacting zinc } \\
\text { finger protein } 1(\mathrm{ClZ1} \text { ) expression; useful to } \\
\text { diagnose and treat, e.g., lung cancer. }\end{array}$ & $\begin{array}{l}\text { Cizzle Biotechnology } \\
\text { (Heslington, UK) }\end{array}$ & Coverley D & 2/5/2009 & $8 / 12 / 2010$ \\
\hline $\begin{array}{l}\text { WO } 2010061697, \\
\text { JP } 2010148491\end{array}$ & $\begin{array}{l}\text { A method of diagnosing normal tension glaucoma } \\
\text { by identifying at least one single nucleotide poly- } \\
\text { morphism in the polymorphic region containing, } \\
\text { e.g., TOM 1-like protein } 1 \text {, synaptotagmin-like } 3 \text {, } \\
\text { dedicator of cytokinesis } 2 \text {, zinc finger protein } 407 \\
\text { or tankyrase-1. }\end{array}$ & Menicon (Nagoya, Japan) & Mizuki N & $11 / 27 / 2008$ & $\begin{array}{l}6 / 3 / 2010 \\
7 / 8 / 2010\end{array}$ \\
\hline WO 2010055024 & $\begin{array}{l}\text { A method of enhancing yield-related traits in plants } \\
\text { relative to control plants, involving modulating } \\
\text { expression of a nucleic acid encoding YLD-zinc } \\
\text { finger polypeptide comprising zf-DNL domain in a } \\
\text { plant. }\end{array}$ & $\begin{array}{l}\text { BASF Plant Science } \\
\text { (Ludwigshafen, Germany) }\end{array}$ & $\begin{array}{l}\text { Frankard V, Hatzfeld Y, } \\
\text { Reuzeau C, } \\
\text { Sanz Molinero Al }\end{array}$ & $11 / 12 / 2008$ & 5/20/2010 \\
\hline CN 101671676 & $\begin{array}{l}\text { A peanut } \mathrm{C}_{2} \mathrm{H}_{2} \text {-type salt-resistant zinc finger } \\
\text { protein gene } A h Z F P 1 \text {, where the nucleotide } \\
\text { sequence is shown as fully defined } 835 \mathrm{bp} \\
\text { (SEQ ID NO: } 1 \text { ). }\end{array}$ & $\begin{array}{l}\text { Shandong Peanut } \\
\text { Research Institute } \\
\text { (Qingdao, China) }\end{array}$ & $\begin{array}{l}\text { Chen M, Jiang Y, } \\
\text { Pan L, Ren Z, Yang Q, } \\
\text { Yu S, Zhu F }\end{array}$ & 9/9/2008 & 3/17/2010 \\
\hline
\end{tabular}

Source: Thomson Scientific Search Service. The status of each application is slightly different from country to country. For further details, contact Thomson Scientific, 1800 Diagonal Road, Suite 250, Alexandria, Virginia 22314, USA. Tel: 1 (800) 337-9368 (http://www.thomson.com/scientific). 